\title{
Metodologias ativas e trabalho coletivo em sala de aula: a produção de vídeo como pesquisa e prática pedagógica em História ${ }^{1}$
}

\author{
Active methodologies and collective work in the classroom: \\ the production of video as research and pedagogical \\ practice in History
}

Marcela Adriana Grandi ${ }^{2}$

Vanessa Oechsler ${ }^{3}$

\section{Resumo}

Este artigo apresenta uma prática pedagógica nas aulas de História, utilizando a produção de vídeo. A prática é embasada nos conceitos de metodologias ativas, produção de vídeo, relações de seres humanos com mídias, trabalho coletivo e História. $\mathrm{O}$ trabalho foi desenvolvido com alunos do segundo ano do ensino médio, em uma escola estadual de Gaspar (SC). A metodologia pauta-se nas cinco etapas da pedagogia histórico-crítica (SAVIANI, 2005). As aulas foram ministradas pela primeira autora deste artigo e os dados foram obtidos via transcrição das orientações aos alunos e por meio da elaboração de um diário de bordo. A aquisição de autonomia do estudante e a importância da mediação docente nesse processo são evidentes, em que os alunos desenvolveram o trabalho coletivo, transcorrido em duas esferas: seres humanos com mídias e sujeitos históricos protagonistas do processo de construção de conhecimento.

Palavras-chave: Educação. Mediação. Metodologias ativas.

\begin{abstract}
This article presents a pedagogical practice in History classes, using video productions. The practice is based on the concepts of active methodologies, video productions, relation of human beings with the media, collective work and History. The work was carried out with students of the second year of high school in a public school of Gaspar (SC). The methodology is based on the five steps of historical-critical pedagogy (SAVIANI, 2005). The classes were taught by the first author of this article and the data were obtained through the transcription of guidelines to students and the preparation of a logbook. The student's acquisition of autonomy and the importance of teaching mediation in this process are evident, where students developed collective work, carried out in two spheres: human beings with media and main historical subjects of the knowledge building process.
\end{abstract}

Keywords: Education. Mediation. Active methodologies.

1 Síntese do trabalho de conclusão de curso de Especialização em Pesquisa e Prática Pedagógica do Instituto Federal de Santa Catarina (IFSC), Gaspar, SC, Brasil, defendido em 22.05.20, sob a orientação da Prof ${ }^{\text {a }}$. Dra ${ }^{\text {a }}$ Vanessa Oechsler.

2 Bacharel e licenciada em História pela Fundação Universidade Regional de Blumenau (FURB), Blumenau, SC e especialista em Pesquisa e Práticas Pedagógicas pelo IFSC. Docente na Rede Estadual de Ensino de Santa Catarina. ORCID: https://orcid.org/0000-0003-40256150. E-mail: marcela.g03@aluno.ifsc.edu.br

3 Doutora em Educação Matemática pela Universidade Estadual Paulista Júlio de Mesquita Filho (UNESP), Rio Claro, SP, Brasil e mestre em Ensino de Ciências Naturais e Matemática pela FURB. Professora do Instituto Federal de Educação Ciência e Tecnologia de Santa Catarina (IFSC), Gaspar, SC. ORCID: https://orcid.org/0000-0002-1852-4385. E-mail: vanessa.oechsler@ifsc.edu.br 


\section{Introdução}

O presente artigo traz os resultados de pesquisa-ação que tem por temática o uso de metodologias ativas de produção de vídeo nas aulas de História. A problemática concentra-se em analisar de que maneira a produção de vídeo promove o trabalho coletivo em sala de aula. A aplicação do projeto ocorreu em 2019, em uma escola da rede estadual de ensino, no município de Gaspar (SC), e teve como público-alvo uma turma do segundo ano do ensino médio, com vinte e um (21) estudantes.

A problemática da pesquisa tornou-se evidente frente às observações da pesquisadora quanto à necessidade de pensar em uma prática pedagógica que promovesse um processo de ensino de acordo com a perspectiva de aprendizagem democrática de Paulo Freire (2000), ou seja, que torne todos os conhecimentos acessíveis a todos os indivíduos que o compõe.

Nesse sentido, Klein (2012) afirma que:

Não se deve impor um projeto fechado de curso, mas um programa com as grandes diretrizes delineadas, no qual se vai construindo caminhos de aprendizagem em cada etapa, estando atentos - professor e alunos - para avançar, da forma mais rica possível, em cada momento. (KLEIN, 2012, p.13).

Para tanto, foi necessário levar em consideração os saberes empíricos do educando, aliando-os aos saberes científicos adquiridos no âmbito escolar. Segundo Bagno (2008):

O importante é mostrar aos alunos que existe na escola uma vontade de acompanhar as transformações que estão se processando do lado de fora da sala de aula e que todos os meios e multimeios oferecidos pelas novas tecnologias também devem ser usados para tornar o aprendizado mais atraente, mais atualizado, mais vivo. (BAGNO, 2008, p. 62).

Grandi e Oechsler (2019) corroboram Bagno e afirmam que o uso de tecnologias, cada vez mais comum à geração nascida na era digital, traz à tona a necessidade de adaptação das práticas escolares.

O trabalho com mídias em sala de aula exige um posicionamento crítico e reflexivo. Faz-se necessário, portanto, que o professor saia da zona de conforto e se arrisque na "zona de risco", ou seja, encare o uso das tecnologias digitais tão naturais aos alunos, mas que representem um terreno inóspito aos professores. O medo de encarar esse risco faz com que muitos professores resistam ao uso de tecnologias digitais ou ainda não explorem as suas contribuições à educação (BORBA; PENTEADO, 2007).

Nesse sentido, a partir dos estudos de Borba e

\section{Zulatto, Chiari (2015) coloca que}

[...] práticas colaborativas com os pares e com os próprios alunos podem possibilitar que a zona de risco se torne zona de conforto, quando buscamos nos sentir confortáveis com o risco. Dessa forma, é possível que as possibilidades abertas por novas tecnologias sejam, de fato, exploradas. (CHIARI, 2015, p. 42).

A proposta pedagógica apresentada neste artigo incentivou o trabalho coletivo entre alunos e professores na produção de um vídeo na aula de História, buscando, dessa forma, em um trabalho conjunto, diminuir essa sensação de desconforto do professor, ao inserir tecnologias em sala de aula.

Por pressuposto teórico, esta pesquisa defende que o uso de metodologias ativas de produção de vídeo pode promover o trabalho coletivo em sala de aula, uma vez que propicia o desenvolvimento de princípios de cooperação e colaboração necessários à formação do educando, enquanto ser social. Esse trabalho coletivo acontecerá, se forem organizados espaços em sala de aula para o trabalho em equipe, bem como a discussão e a reflexão sobre a atividade a ser desenvolvida. Os objetivos desta pesquisa concentraram-se em planejar e aplicar uma prática pedagógica com o foco no uso de metodologias ativas, elencando quais as contribuições delas para o ensino; implementar a produção de vídeo, como pesquisa e prática pedagógica em sala de aula, além de identificar de que forma o trabalho coletivo se desenvolve ao longo do processo de produção de vídeo.

Apresenta-se uma proposta pedagógica que não só contemple tais aspectos, mas demonstre a possibilidade de adequação dos métodos de ensino de forma simples e prática, apontando os desafios e riscos de tal proposta, mas, principalmente, discutindo as possibilidades e caminhos para rompê-los.

Cabe ressaltar que, embora a disciplina escolhida para a aplicação do projeto seja a História, bem como a temática escolhida no documentário, concentre-se em aspectos e processos ocorridos como história, considera-se que esta proposta pedagógica pode ser aplicada em qualquer disciplina e/ou em interdisciplinaridade com os demais componentes curriculares.

Na próxima seção, apresenta-se o referencial teórico utilizado como embasamento para o alcance dos objetivos propostos na aplicação e desenvolvimento da pesquisa.

\section{Fundamentação teórica}

A presente pesquisa se desenvolveu sob a perspectiva das metodologias ativas. As metodologias ativas 
apresentam-se como ferramentas no processo de compreensão do mundo que cerca o educando uma vez que são entendidas como uma prática pedagógica reflexiva. O aluno assume o papel de protagonista em seu próprio processo de aprendizagem, pois torna-se ativo e participativo, desenvolvendo a autonomia e a criticidade necessárias ao sujeito histórico (DIESEL; BALDEZ; MARTINS, 2017; LOVATO et al., 2018; MORAN, 2017). Cabe ressaltar que as metodologias ativas não são um método novo de ensino. Dewey, com a Escola Nova (1950), Freire com a educação progressista (1996), Ausubel com a aprendizagem significativa (1980) já pregavam uma educação em que o aluno fosse o agente ativo da sua aprendizagem, e o professor fosse o mediador desse processo educativo (DIESEL; BALDEZ; MARTINS, 2017; LOVATO et al., 2018). Diante do cenário social atual, em que as tecnologias e fenômenos digitais seguem em crescente desenvolvimento, essa discussão sobre $o$ aluno no centro do processo de aprendizagem surge com o nome de metodologias ativas. Nesse contexto, é importante que os educadores que objetivam transformar suas práticas pedagógicas de maneira a contribuir de forma significativa na formação de seus educandos busquem maneiras de inserir tais questões no processo de ensino e aprendizagem. Ao empenhar-se nesse ofício, o professor deixa a prática hierárquica e assume o papel de mediador do processo de ensino (TORRES; ALCANTARA; IRALA, 2004).

As metodologias ativas podem apresentar-se como contraponto ao método tradicional, elevando os alunos de uma postura passiva a uma postura crítica e de movimento, partindo de suas próprias concepções, para transformá-las ao longo do processo de construção de conhecimento (DIESEL; BALDEZ; MARTINS, 2017).

Uma vez entendidos tais princípios, destaca-se a produção de vídeo como um dos instrumentos de inserção de metodologias ativas no processo de ensino. Nessa atividade, $o$ aluno tem autonomia para escolher a forma de abordagem do tema ou como explicará o conteúdo, quais modos serão utilizados (sons, imagens, entre outros), para comunicar seu entendimento e ideias (OECHSLER, 2018).

Nessa perspectiva, cabe mencionar que a construção de conhecimento se dá por meio do trabalho coletivo e, no caso da produção de vídeo em sala de aula, esse trabalho coletivo envolve tanto elementos humanos, como os atores envolvidos no processo (alunos, professores, pais, entre outros), quanto elementos não humanos (Internet, câmera, software de edição, entre outros). De acordo com Borba e Villarreal (2005), embasados em Lévy (1993), as tecnologias também são atores no processo de produção do conhecimento. Apesar de essas tecnologias terem sido produzidas por humanos, Borba e Villarreal (2005) utilizam a expressão atores não humanos para diferenciar quando falam dos seres humanos (atores humanos) e quando falam das mídias (atores não humanos) nos seus trabalhos. Essas relações entre atores humanos e não humanos são fundamentais, sobretudo nos dias atuais, no processo de produção de conhecimento. Segundo Borba e Penteado (2007, p. 48).

[...] os seres humanos são constituídos por técnicas que estendem e modificam seu raciocínio e, ao mesmo tempo, esses seres humanos estão constantemente transformando essas técnicas. Assim, não faz sentido uma visão dicotômica. Mais ainda, entendemos que o conhecimento é produzido com uma determinada mídia, ou com uma tecnologia da inteligência. É por isso que adotamos a perspectiva teórica que se apoia na noção de que o conhecimento é produzido por um coletivo formado por seres humanos com mídias.

As observações dos autores sobre seres humanos com mídias estão pautadas nas ideias de Lévy (1993) e Tikhomirov (1981). Tikhomirov defende que os computadores afetaram a cognição humana e que eles podem mudar a educação na maneira como o conhecimento é adquirido. Já Levy não desconsidera a afirmação de Tikhomirov, mas defende que a oralidade e a escrita também podem ser vistas como tecnologias. O surgimento da escrita possibilitou o desenvolvimento de um pensamento linear que, posteriormente, foi rompido pela tecnologia, a qual traz sons, imagens e vídeos aliados à escrita e à oralidade, ou seja, propõe multimeios para composição do conhecimento, produzindo uma extensão de nossa memória (SOUTO, 2013).

Borba e Villarreal (2005) expandem essas ideias, afirmando que a relação dialógica entre os seres humanos e as mídias (materiais ou imateriais), promove uma produção coletiva de conhecimento, em que as mídias podem condicionar a forma como os seres humanos pensam, ao mesmo tempo em que são moldadas por eles.

Essa produção coletiva se estende nas relações interpessoais inerentes ao processo de ensino, promovendo um processo democrático e igualitário, uma vez que educando e educadores são tratados em uma relação horizontal, em que ambos têm o papel de atores no processo (BORBA; OECHSLER, 2018).

É aqui que se encontra a relação entre a 
aprendizagem colaborativa, o trabalho coletivo e metodologias ativas, uma vez que a tecnologia se apresenta como fator facilitador para o desenvolvimento do trabalho cooperativo e colaborativo, já que viabiliza a socialização de ideias e possibilita a construção de conhecimento de forma democrática e igualitária entre os atores humanos envolvidos.

Nesse sentido, cabe abordar as questões relativas ao trabalho coletivo em sala de aula, que pode ser entendido como absorção de conhecimento de forma partilhada e por meio de interação social que ocorre sob a ótica da cooperação e colaboração. Ambas as práticas, cooperação ou colaboração "enfatizam uma maior responsabilização dos aprendizes no seu processo de aprendizagem, colocando-os como partícipes na construção do conhecimento". (TORRES; IRALA, 2014, p. 69).

Resumindo, portanto, observa-se, nesses diversos conceitos, que os termos "cooperação" e "colaboração" designam atividades de grupo que pretendem um objetivo em comum. Apesar de suas diferenciações teóricas e práticas, ambos os conceitos derivam de dois postulados principais: de um lado, da rejeição ao autoritarismo, à condução pedagógica com motivação hierárquica, unilateral. De outro, trata-se de concretizar uma socialização não só pela aprendizagem, mas principalmente na aprendizagem. (TORRES; ALCANTARA; IRALA, 2004, p. 6).

Sendo assim, pode-se dizer que "qualquer atividade, desenvolvida em conjunto, animada por um objetivo final que leve a aquisições determinadas, é uma aprendizagem colaborativa". (TORRES; ALCANTARA; IRALA, 2004, p. 6).

O foco, em um objetivo final aliado à ideia de grupo ou equipe, "[...] permite ao grupo [...] constituir-se em apoio para o processo individual de cada um". (PEIXOTO; CARVALHO, 2007, p. 195).

É importante destacar que, apesar de o trabalho colaborativo ter sua origem no trabalho em grupo, o simples fato de se ter um grupo não implica um trabalho colaborativo, pois, segundo Torres e Irala (2014, p. 65):

Em um contexto escolar, a aprendizagem colaborativa seria duas ou mais pessoas trabalhando em grupos com objetivos compartilhados, auxiliando-se mutuamente na construção de conhecimento. Ao professor, não basta apenas colocar, de forma desordenada, os alunos em grupo, deve sim criar situações de aprendizagem em que possam ocorrer trocas significativas entre os alunos e entre esses e o professor.

Nesse sentido, para que a aprendizagem colaborativa alcance bons resultados, é necessário haver um planejamento de atividades que visem a desafios, a rupturas e à reflexão (TORRES; ALCANTARA; IRALA, 2004).

Portanto, a aprendizagem coletiva tem como motriz o trabalho coletivo que pode organizar-se de forma cooperativa e/ou colaborativa. Para melhor compreensão desenvolveu-se o quadro $1 \mathrm{com}$ as características de cada um, tendo como base as análises de Peixoto e Carvalho (2007), Torres e Irala (2014) e de Torres, Alcantara e Irala (2004).

Neste trabalho, realizou-se uma atividade coletiva entre atores humanos (alunos e professor) e atores não humanos (Internet, jornais, câmera, software de edição, entre outros) na produção de um vídeo com conteúdo de História.

No que se refere à disciplina de História, pode-se dizer que seu foco de estudo se concentra em tudo aquilo que os homens viveram, sentiram, pensaram e produziram ao longo do tempo (BLOCH, 2002). Porém, cabe fazermos uma distinção entre História com $\mathrm{H}$ maiúsculo e história com h minúsculo.

Segundo Funari (2011), história com h minúsculo, refere-se ao conjunto de relatos, narrativas e percepções gerais sobre fatos e vivências particulares sob cada acontecimento histórico. Tais relatos encontram-se carregados de retórica, ou seja, de uma organização e seleção prévia do que se dizer. Essa seleção pode, portanto, excluir ou acrescentar informações reais e irreais sobre o fato. Já a palavra História com $\mathrm{H}$ maiúsculo, tem sua origem na Grécia Antiga e traz em seu significado a investigação e/ou pesquisa. Ela difere de história, uma vez que busca investigar tais narrativas sob o ponto de vista científico e crítico, não se atendo apenas ao livre relato:

Heródoto e Tucídides não queriam apenas narrar ou explicar, defendiam, mirando-se nos logoi da praça pública, um ponto de vista sobre a sociedade da qual faziam parte, Atenas, e seu sistema político, fundado, precisamente, na isegoria (igualdade de fala, liberdade de expressão). (FUNARI, 2011, p. 143).

A História reveste-se de elementos e de métodos que a tornam ciência que produz conhecimento sobre os acontecimentos. Esse processo de composição e análise da História tem seu início em pequenos acontecimentos relacionados ao cotidiano e a histórias locais, uma vez que:

A História [...] nunca se debruçou sobre a história humana como um todo, mas sobre histórias particulares, histórias de ALGO. Sempre estudou histórias específicas inseridas dentro de unidades de sentido (os ALGOS) que conferiam coerência a um corpo de documentos e a uma 
narrativa, descrição, explicação ou interpretação. (GUARINELLO, 2004, p. 4)

Por essa razão, optou-se pela abordagem da história local neste trabalho, uma vez que seu estudo proporciona maior proximidade do educando com o meio que o cerca e faz com que ele perceba como essa relação implica transformação e interferência na sua história pessoal, estabelecendo o maior envolvimento e sentimento de pertencimento ao grupo social em que está inserido (ZAMBONI apud BARROS, 2013).

Por história local entende-se:

[...] a história que trata de assuntos referentes a uma determinada região [...]. Apesar de estar relacionada a uma história global, a história local se caracteriza pela valorização dos particulares, das diversidades, ela é um ponto de partida para formação de uma identidade regional. (BARROS, 2013, p. 15).

Utilizar a história local no processo de ensino de História contribui para a ampliação das concepções que se tem sobre o processo do aprender História e a relação com a sociedade à qual o educando pertence (GERMINARI; BUCZENKO, 2012).

Ao entender o espaço em que está inserido, o estudante começa a construir sua identidade e a entender-se como agente transformador do espaço em que vive. Cabe ressaltar que:

[...] a tarefa da disciplina de História é fornecer ao estudante um senso de identidade que estimule e facilite sua cooperação com o outro [...]. (BARROS, 2013, p. 9).

Quadro 1 - Características do trabalho coletivo (cooperativo e colaborativo)

\begin{tabular}{|c|c|}
\hline Cooperativo & Colaborativo \\
\hline $\begin{array}{l}\text { - Precisa de mediação e controle sobre as } \\
\text { interações, para promover autonomia, } \\
\text { realizar tarefas, desenvolver a capacida- } \\
\text { de de trabalho em grupo e alcance dos } \\
\text { objetivos. } \\
\text { - É a melhor opção como método de ini- } \\
\text { ciação ou preparação para a colaboração. } \\
\text { - Objetivos: a partilha é entendida como } \\
\text { divisão de todo o trabalho em partes: } \\
\text { subtarefas. } \\
\text { - O grupo realiza a tarefa ao juntar as } \\
\text { partes. } \\
\text { - Resulta em uma obra coletiva: contribui- } \\
\text { ção de cada um é imprescindível para o } \\
\text { resultado final (interdependência). } \\
\text { - Tarefarefas se completam (interdependência). } \\
\text { terá sentido ao juntar-se com a parte do } \\
\text { outro (interdependência). } \\
\text { - Divisão: } 1^{\circ} \text { subtarefa por grupo } \\
2^{\circ} \text { subtarefa individual. } \\
\text { - Relações de dependência entre os mem- } \\
\text { bros dos grupos. } \\
\text { - Construção grupal de ideias. } \\
\text { - Conhecimento é resultado do consenso } \\
\text { entre os membros da sociedade, pois é } \\
\text { construído na dialética e nas relações } \\
\text { sócio -interacionistas. }\end{array}$ & $\begin{array}{l}\text { - Mais adequado aos sujeitos autônomos. } \\
\text { - Exige maturidade e responsabilidade. } \\
\text { - Garante maior liberdade aos participantes. } \\
\text { - Exige troca de informações e discussão no } \\
\text { grande grupo; } \\
\text { - Objetivo: A partilha é entendida como } \\
\text { participação, compartilhar ideias. } \\
\text { - Cada membro, individualmente, buscará } \\
\text { o alcance dos objetivos. } \\
\text { - Não há discussão de tarefas por grupo de } \\
\text { trabalho. Todos fazem tudo. } \\
\text { - O grupo oferece apoio como recurso } \\
\text { para compartilhar discussões e opiniões } \\
\text { individuais. } \\
\text { - O grupo oferece os recursos para que o } \\
\text { indivíduo alcance sozinho o objetivo. } \\
\text { - Ina exclui a tarefa cooperativa, uma vez } \\
\text { - Possui caráter associativo. } \\
\text { - Relaçõos martilhamento de ideias. } \\
\text { - Possibilita aos indivíduos es participação ati- } \\
\text { va no grupo, desenvolvimento progressivo } \\
\text { de autonomia, desenvolvimento de com- } \\
\text { petências, exige participação no grupo, } \\
\text { oferece apoio necessário. }\end{array}$ \\
\hline
\end{tabular}

Fonte: Os autores (2020). 
Abordar a importância da História na sociedade, bem como evidenciar o papel do aluno/indivíduo como agente construtor e transformador da história, teve a intencionalidade de levar os educandos a questionar a ideia que se tem de que história é apenas passado e está focada nos grandes "heróis", conduzindo-os à compreensão de que a história é feita por cada um de nós, que somos, ao mesmo tempo, agentes da história e também seu objeto de estudo, caracterizando-nos como sujeitos da história (COTRIM; RODRIGUES, 2014).

Além disso, é preciso romper com o que Andrade (2018, p. 175) define como papel de passividade diante da História, a fim de torná-la atrativa e compreensível ao aluno, pois:

Essa passividade causa problemas, especificamente porque, uma vez que os alunos não se entendem diante dos processos históricos, fica mais difícil à disciplina de História lhes interessar. É justamente, quando o ensino entra no campo do desinteresse que surge o grande desafio para a escola e, sobretudo, para os professores, exigindo mudanças rápidas no perfil didático.

Dessa forma, por meio do estudo da história local, o aluno constrói sua identidade como agente transformador do espaço em que vive. Tal interação ocorre de forma cooperativa. Daí a relação entre História e o trabalho cooperativo.

Na próxima seção, serão apresentados os passos de como este trabalho foi desenvolvido em sala de aula.

\section{Metodologia}

Esta pesquisa constitui-se como investigação de natureza aplicada, pois buscou a elaboração e aplicação de uma prática pedagógica com foco no uso da metodologia ativa de produção de vídeo e como tal prática promove o trabalho coletivo em sala de aula. Caracteriza-se como uma pesquisa de abordagem qualitativa, uma vez que a coleta e a análise de dados ocorreram de forma subjetiva, por meio de observação de resultados, da transcrição das orientações dadas aos alunos, assim como, pela elaboração e análise de um diário de bordo com as observações da pesquisadora, durante o desenvolvimento das etapas de produção de vídeo. Quanto aos procedimentos de pesquisa adotados, refere-se à pesquisa-ação, uma vez que objetivou promover o protagonismo discente e seguiu uma aplicação organizada e sistemática, que levou em consideração os conhecimentos empíricos iniciais do educando, para o desenvolvimento de uma compreensão vivencial da sociedade.
A aplicação deste projeto de pesquisa-ação segue a metodologia da pedagogia histórico crítica representada por Saviani (2005) que defende uma educação transformadora, crítica, construtiva e que leve em consideração os saberes e vivências sócio-históricas dos educandos. Nesse sentido, a aprendizagem é fruto da interação entre os indivíduos e os mediadores, uma vez que é constituída socialmente nas relações humanas (LEITE; LEITE; PRANDI, 2009).

Gasparin (2005) sistematiza a teoria da pedagogia histórico crítica de Saviani, atentando para a importância da submissão do espontaneísmo pedagógico a uma rigorosidade metódica, criando, assim, uma metodologia dividida em:

- prática social inicial (ponto de partida sobre quem é o sujeito e seu lócus de fala);

- problematização (questionamentos sobre o cotidiano e o prático);

- instrumentalização (método e definição de recursos e conhecimentos necessários para $\mathrm{o}$ desenvolvimento);

- catarse (desenvolvimento e síntese dialética de absorção do conteúdo);

- prática social final (devolutiva e consequente transformação social).

A metodologia de trabalho desta pesquisa foi dividida de acordo com cada uma das cinco etapas mencionadas acima. Como prática social inicial, realizou-se uma discussão pautada nos seguintes temas norteadores: os conhecimentos dos estudantes sobre técnicas de edição de vídeos; análise da influência e do grande desenvolvimento de conteúdos digitais; discussão sobre o fenômeno dos Youtubers, bem como o alcance desses meios para difusão de conhecimentos. O objetivo dessa primeira etapa foi evidenciar quais os saberes prévios dos educandos sobre essa temática. Sendo assim, os alunos puderam expor os tipos de vídeos a que costumavam assistir e quais os conhecimentos adquiridos e/ou compartilhados, através deles.

Ainda nessa etapa, realizou-se a apresentação da proposta do projeto pedagógico de produção de vídeo em História, que consistiu na elaboração de um documentário histórico, tendo como pano de fundo uma temática relacionada à história local.

A partir de então, ocorreu a segunda etapa de aplicação do projeto: a problematização, em que teve início o processo de discussão de ideias sobre possíveis temas e definição de objetivo de pesquisa que resultaria na produção de vídeos. A decisão pelo tema foi tomada pela turma toda, mediante votação. 
O tema escolhido foi "Mistério e morte de Ivo Renaux, em Brusque-SC, na década de 1940". Trata-se da morte do empresário Ivo Renaux, ocorrida em Brusque/ SC, em 1949. Configura-se como um mistério uma vez que, de acordo com os meios de investigação da época, não ficou comprovado tratar-se de suicídio ou de homicídio praticado pela esposa de Ivo. O tema torna-se relevante para a comunidade local, devido à importância da família Renaux no processo de industrialização e desenvolvimento no ramo têxtil e sua relação com o crescimento e desenvolvimento de Brusque e região.

Com o tema definido, partiu-se para a terceira etapa de aplicação do projeto: a instrumentalização dos alunos para o alcance dos objetivos. Nessa etapa, foram apresentadas várias modalidades de vídeos (animação, vídeo com material manipulativo, documentário e etc), conforme indicam Oechsler, Fontes e Borba (2017), para que o grupo, de forma coletiva, definisse qual modalidade seria adotada. Além disso, foram disponibilizados aos alunos alguns textos, contendo etapas da produção de vídeo, como elaborar um roteiro, por exemplo. (Os textos utilizados para instrumentalização dos alunos e fichamentos foram: Hampe (1997), Lúcide e Kalil (2012) e Oechsler, Fontes e Borba (2017). No prazo de uma semana, os alunos deveriam ler e realizar o fichamento desses textos, a fim de formar um referencial para a elaboração das etapas de trabalho.

Na quarta etapa, entendida como catarse, os alunos foram divididos em grupos de trabalho, de acordo com as etapas da produção de vídeo explicitadas nos estudos de Oechsler, Fontes e Borba (2017). Cada aluno pôde optar em qual grupo de trabalho gostaria de atuar, tendo em vista suas habilidades para o cumprimento das tarefas propostas. Caso desejasse, $o$ mesmo estudante poderia fazer parte de mais de um grupo de trabalho. A pesquisa acerca da temática foi desenvolvida por todos os alunos, independentemente da equipe em que estavam inseridos. Os grupos de trabalho foram definidos como: análise de dados; roteiro geral; atores; materiais; entrevistas e filmagem/ edição de vídeos. As funções de cada grupo de trabalho são descritas no quadro 2 .

Quadro 2 - Separação das funções de cada grupo de trabalho no projeto de produção de vídeo

\begin{tabular}{|c|c|}
\hline \multicolumn{2}{|r|}{ Grupos de trabalho } \\
\hline GTs & Função \\
\hline Roteiro geral & $\begin{array}{l}\text { - Elaboração de roteiro geral do documentário. } \\
\text { - Detalhar as etapas de produção do documentário. }\end{array}$ \\
\hline Análise de dados & $\begin{array}{l}\text { - Junção de toda a pesquisa bibliográfica, iconográfica, } \\
\text { documental realizada pela turma. } \\
\text {. Redação de um texto com a versão final sobre o fato. }\end{array}$ \\
\hline Atores & $\begin{array}{l}\text { - Elaboração de um roteiro de falas. } \\
\text { - Definir os papéis que serão representados. }\end{array}$ \\
\hline Materiais & $\begin{array}{l}\text { - Figurino. } \\
\text { - Cenário (consultar roteiro de cena). } \\
\text {. Verificar materiais necessários em cada grupo de trabalho. }\end{array}$ \\
\hline Entrevistas & $\begin{array}{l}\text { - Elaborar uma lista de possíveis entrevistados. } \\
\text { - Elaborar um roteiro de entrevista contendo as perguntas. } \\
\text {. Coleta de assinatura nos termos de concessão de entrevista. }\end{array}$ \\
\hline Filmagem/edição de vídeos & $\begin{array}{l}\text { - Elaborar um roteiro de cena. } \\
\text { - Fazer as filmagens e a edição de vídeos. } \\
\text { · Junção das imagens, vídeos e efetivação do roteiro. }\end{array}$ \\
\hline
\end{tabular}

Fonte: Os autores (2020).

Com os grupos de trabalho formados, seus membros deveriam traçar as estratégias e ações a serem desenvolvidas. As orientações aos grupos ocorreram no horário de aula, em que foram oferecidas aos alunos orientações por grupo/etapa de produção, com esclarecimento de dúvidas e acompanhamento do cumprimento das atividades idealizadas pelo grupo.

Após três semanas de orientação aos grupos, realizou-se uma reunião geral com o intuito de apresentação e exposição das ideias de cada grupo de trabalho, bem 
como a redação de um projeto de pesquisa e elaboração do documentário em História, sintetizando toda a discussão e pesquisa já empreendida pelos alunos.

A partir de então, ainda na etapa de catarse, os alunos deram início às filmagens e edição de imagens que iriam compor o documentário. Devido aos horários de trabalho no contra turno escolar e a inviabilidade de encontros fora do ambiente escolar, os alunos optaram por efetuar as filmagens na escola e no horário de aula. Assim sendo, foi cedido o total de oito aulas para realização das filmagens de cada cena que compunha a dramatização da morte de Ivo Renaux.
Em sequência, os alunos deram início à junção e edição de cada filmagem e cena para composição do documentário. Ao fim de dois meses de trabalho, os alunos apresentaram uma prévia do documentário. Nesse dia, realizaram-se novas discussões entre os grupos de trabalho, para possíveis correções e/ou inserções de cena.

Como prática social final, última etapa de trabalho, os alunos apresentaram a versão final de seu documentário em uma seção de vídeos na sala de aula.

A metodologia de aplicação deste projeto pode ser exemplificada pela figura 1 .

Figura 1 - Infográfico com a metodologia de desenvolvimento do trabalho de acordo com a pedagogia histórico-crítica

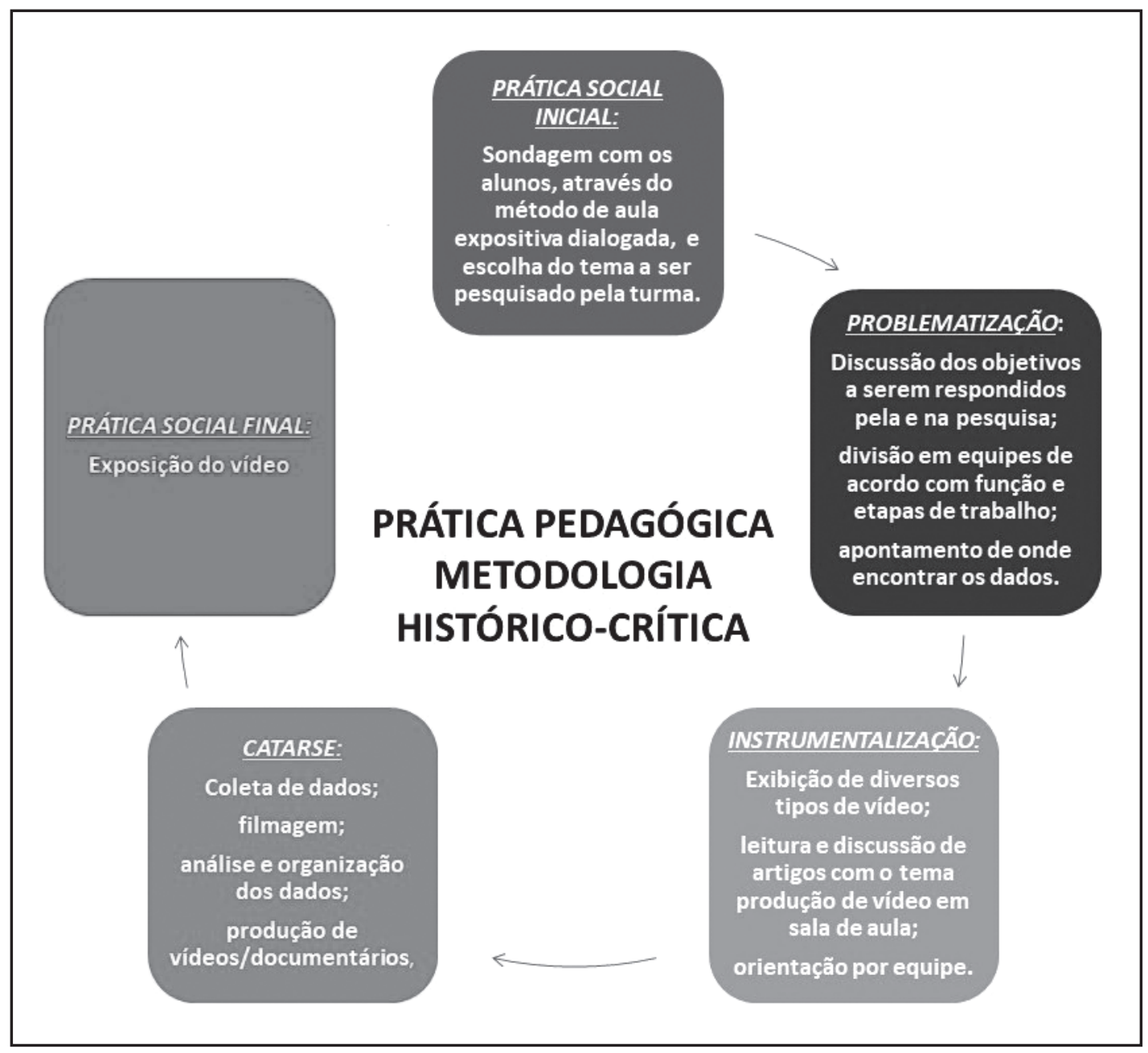

Fonte: Os autores (2020).

Uma vez explicada a metodologia do desenvolvimento do trabalho, parte-se para a análise dos resultados e dados obtidos na pesquisa.

\section{Resultados e discussões}

Seguindo o já descrito na metodologia, na primeira etapa, com o intuito de suscitar a discussão, deu-se 
início a uma roda de conversa em que os alunos e a professora puderam expor seus conhecimentos e interesses em relação à temática da produção de vídeo. Os alunos relataram já terem produzido alguns vídeos, tanto para apresentação de trabalhos de outras disciplinas, como para algumas atividades ligadas aos programas oferecidos na escola.

Constatou-se também um grande conhecimento, por parte dos educandos, quanto aos materiais que precisariam utilizar para as filmagens e edições de vídeos. Citaram, nessa conversa, gostar muito de vídeos e canais do YouTube que trazem curiosidades e novas descobertas, inclusive na área de História, ficando evidente o potencial dinâmico e alcance das produções audiovisuais. Nessa perspectiva, Oechsler (2015, p. 2) afirma que:

[...] os vídeos caracterizam uma questão de dinamicidade, utilizando diversas ferramentas multimídias [...]. Por esse motivo, os vídeos têm despertado o interesse de professores e pesquisadores. Além disso, eles têm chamado a atenção pelo seu alcance, pois são compartilhados por meio de redes sociais, plataformas virtuais, aplicativos de celular, entre outras formas.

Nesse momento, discutiu-se com os alunos sobre as fontes de informações e a análise crítica dos conteúdos disponibilizados nas redes de internet. Essa instrução é fundamental, uma vez que não existe um filtro para separar produções realmente aceitas pela historiografia e que sejam comprovadamente reais, de outras que misturam acontecimentos históricos com entretenimento na produção dos seus materiais, gerando informações distorcidas ou irreais sobre os fatos.

Ainda nessa discussão inicial, os alunos definiram o tema abordado para execução do documentário. Esse tema surgiu graças a um trabalho realizado no ano anterior para a disciplina de Português. Na ocasião, os alunos estudaram um conto acerca da temática "Mistério e morte de Ivo Renaux, em Brusque/ SC, na década de 1940". O interesse pelo tema era tão grande que o mostrou, não só relevante, mas próximo à realidade dos educandos. É possível comprovar tais elementos na fala da Aluna II que diz:

Na verdade, a nossa professora de Português trouxe na sala um [conto] só falando da história. A professora de História chegou na sala, falando do trabalho, aí a gente gostou da história e foi pesquisar [...].

O tema escolhido pela turma atendeu ao critério de história local, uma vez que a escola está localizada em bairro próximo à cidade de Brusque e a comunidade que ali reside, costuma visitar a cidade vizinha com frequência, o que torna seus hábitos, costumes e história, parte do cotidiano dos alunos, interferindo na formação de identidade desses sujeitos (BARROS, 2013).

Com a temática definida, os alunos deram início à problematização do tema. Questões como possíveis causas do crime ou suicídio, como eram os processos de investigação criminal na época, entre outros, foram amplamente discutidos pelos alunos, o que os levou a empreender pesquisas e busca por respostas às questões. Essa investigação fez com que os estudantes assumissem uma postura ativa e protagonista no processo de aquisição de conhecimento, característica de propostas de metodologias ativas (MORAN, 2017).

$\mathrm{Na}$ instrumentalização, os alunos tiveram contato com artigos científicos, explicando as etapas de elaboração de roteiro. Ao final do prazo para leitura e fichamento dos textos, percebeu-se que a maioria não havia feito a tarefa. Os estudantes demonstraram dificuldade com a leitura e relataram não ser algo habitual a eles, o que causou estranheza na resolução da atividade. Isso dificultou o desenvolvimento dessa etapa de forma autônoma, pois necessitou da intervenção direta da professora, que, por meio de uma aula expositiva, definiu com mais clareza as etapas da produção de vídeo. As orientações precisaram ser mais específicas e detalhar exatamente quais as funções e tarefas que cada equipe precisaria desempenhar, não podendo a professora ser apenas uma mediadora do processo, mas necessitando de uma intervenção mais profunda nessa etapa da atividade.

É preciso lembrar que o processo de aquisição/desenvolvimento de autonomia está intimamente ligado à maturidade dos envolvidos e que os estudantes se encontravam em fase de crescimento e desenvolvimento desta maturidade (PEIXOTO; CARVALHO, 2007).

Devidamente instrumentalizados e organizados em grupos de trabalho, os alunos precisavam organizar as tarefas a serem realizadas. A junção desses planejamentos daria origem a um projeto único de pesquisa. Ao realizar-se a reunião para redigir tal projeto, procurou-se observar o nível de compreensão quanto à importância de um roteiro para elaboração do documentário. Um dos alunos da equipe de roteiro descreveu o que compreendeu:

\footnotetext{
Ah, montar o roteiro é pegar os dados. Primeiro, tem que saber o que aconteceu, daí a gente bota no papel: Ah, aconteceu isso. Aí tem que escrever isso e como a gente vai narrar o documentário, a gente vai escrever. $\mathrm{Na}$ entrevista a mesma coisa. Tem que fazer um roteiro pra entrevista: as perguntas,
} 
o que tem pra falar sobre isso. (ALUNO I, 2019).

Outro aspecto evidenciado na fala do aluno é a importância de uma pesquisa detalhada sobre o fato, já que entender como tudo ocorreu era imprescindível para a elaboração do roteiro. A principal fonte de pesquisa, escolhida pela turma, consistiu no site do jornal O Município, de Brusque. Nele, há diversas reportagens sobre a morte de Ivo Renaux, além de entrevistas e relatórios policiais da época.

Cogitou-se ainda a possibilidade de visita ao casarão, onde ocorreu a morte de Ivo, mas descobriu-se que a propriedade foi vendida a um empresário local e encontrava-se em reforma, portanto, fechada para visitação.

A orientação dada aos alunos foi de prosseguir com o projeto, porém pensando em outros locais de filmagem e no uso de vídeos e fotos já disponíveis em outros acervos, desde que citadas as fontes.

A turma considerou inviável a entrevista, uma vez que não havia mais parentes próximos que pudessem relatar versões do fato, além do tempo hábil para elaboração e realização de entrevistas e a falta de acesso às pessoas que constavam na lista de entrevistas (empresário que adquiriu o casarão, e diretora do arquivo histórico de Brusque). Tal fato fica evidente na fala do Aluno III: "Não foi a gente que não quis. Mas foi por terceiros que não deu certo. Foi porque a gente não conseguiu ter acesso e nem se quer falar com alguém [...]".

É possível perceber a necessidade de adequação, uma vez que se pensou em entrevistados (atores humanos no processo), mas a falta de acesso a essas pessoas levou os estudantes a concentrarem-se nas fontes do jornal (atores não humanos). Essa relação seres-humanos com mídia estabeleceu-se de forma colaborativa, uma vez que os alunos, com base nas pesquisas nas mídias, passaram a elaborar o roteiro para representar os próprios atores humanos descritos.

A partir de então, os alunos iniciaram a execução do projeto. Ao longo dessa etapa, apresentaram dificuldade quanto ao cumprimento dos prazos e, mesmo após algumas conversas e replanejamentos de datas e etapas, o documentário parecia não sair do papel. Em uma roda de conversa, os alunos expuseram que as avaliações escolares foram agendadas para uma mesma data ou período e estavam ocorrendo muitos desencontros com os horários pessoais no contra turno, o que acarretou em não conseguirem reunir-se para filmar.

$\mathrm{Na}$ reunião conjunta entre os alunos e a professora, ficou acordado que o roteiro seria modificado e as filmagens ocorreriam na escola e nos horários das aulas de História. As gravações ficaram agendadas para o período após as férias, pois assim os alunos teriam como se dedicar aos demais trabalhos, além de terem tempo de readequar o projeto. Podemos identificar as negociações inerentes ao trabalho coletivo presentes na interação entre os membros que o compõem (TORRES; IRALA, 2014).

Novamente, fez-se necessária a intervenção direta da professora, para definir quais as próximas tarefas que precisariam ser realizadas. Percebeu-se que os alunos se encontravam preocupados com os rumos do projeto, mas não sabiam como seguir. A mediação é fundamental para o trabalho coletivo, como se evidencia a seguir:

Durante os trabalhos em grupo na sala de aula cooperativa, o professor observa as interações de cada grupo, ouve seus debates e faz algumas intervenções, quando julga necessário. Ao final de cada aula, o professor realiza uma sessão para a síntese dos debates, pedindo para que os grupos façam um breve relato oral das suas conclusões ou que submetam uma cópia da atividade realizada em grupos para sua apreciação. (TORRES; IRALA, 2014, p. 68-69).

Após um mês das primeiras filmagens, os alunos deveriam apresentar uma prévia do documentário, porém nada foi apresentado. Novamente os alunos foram questionados sobre quais os fatores que impediam a realização o projeto, ao que responderam que havia falta de iniciativa por parte dos membros das equipes e que a turma, de forma geral, estava delegando a função a um único colega e ele, sem ajuda e colaboração, não conseguia realizar as tarefas, pois não havia um entrosamento do grupo para o desenvolvimento do trabalho coletivo.

Conforme citado anteriormente, os alunos estão em um processo de desenvolvimento de maturidade. A importância de práticas pedagógicas que envolvam o trabalho coletivo em sala de aula, ainda que iniciem de forma cooperativa e caminhem para o colaborativo:
A cooperação ainda é a melhor opção para aqueles integrantes de um grupo que não tem a maturida- de necessária para se engajar numa real colabora- ção, vivenciando de forma confortável e produtiva uma dosagem entre controle exercido e autono- mia concedida. A abordagem cooperativa pode ser considerada como um método de iniciação ou de preparação para a colaboração. Inspiradas pela mesma filosofia, a cooperação e a colaboração se situam numa linha de continuidade. O participan- te do grupo pode, então, ser conduzido a passar 
de uma a outra, cada vez tomando mais decisões e assumindo mais responsabilidades. (PEIXOTO; CARVALHO, 2007, p. 194).

Isso ficou visível ao passo que, após novas orientações e discussões sobre os princípios do trabalho coletivo, ficou acordado que os alunos efetuariam gravações de cena na escola, utilizando-se de mais algumas aulas de História, a começar na semana seguinte. Na data combinada, os alunos retomaram as gravações e não precisaram de intervenção pedagógica, nem da coordenação e nem da professora. Sabiam suas falas e utilizaram os elementos necessários para elaboração do trabalho, além dos materiais necessários para a adequação dos ambientes para filmagem. Houve envolvimento de toda a turma no desenvolvimento do projeto.

Ao analisar a prática dos alunos, sob a luz do referencial teórico desta pesquisa, pode-se afirmar que, nesse momento, o trabalho coletivo deixou de ser cooperativo, com divisões em etapas e funções pré-definidas, para ser colaborativo, onde todos se envolveram na mesma função e com o mesmo objetivo. Isso se evidencia na fala da Aluna IV:

$\mathrm{Na}$ real, é que a gente só fez os grupos na hora que a professora separou, lá, bonitinho. Depois, fez todo mundo junto. Todo mundo se metendo na edição do vídeo, na parte de direção, na parte de atores, foi todo mundo junto na hora [...] lá, no começo, quando a professora chegou e mostrou o trabalho a gente se dividiu em grupo [...]. Aí começou a dar errado [...], aí a professora veio e deu a bronca, aí a gente fez todo mundo junto[...] (ALUNA IV, 2019).

Aos poucos, os alunos foram adquirindo a autonomia necessária para conclusão do projeto. Essa autonomia não anula a importância da mediação docente. É preciso lembrar que o acompanhamento constante do professor em todo processo, ainda que tenha a interpretação de cobrança, traz ao aluno o chamado quanto à responsabilidade e comprometimento necessário para o sucesso da atividade, provando ao próprio educando que ele é capaz de fazer jus ao papel de protagonista de seu processo de aprendizagem. É o que podemos constatar nesta outra fala da aluna IV:

A gente se dividiu no começo em várias equipes. Cada um tinha uma tarefa. Aí a gente só ficou nisso. E ninguém mais gravava. A gente começou a dar pra trás. Aí a professora teve que vir e dar uns puxões de orelha na gente. Aí começou a andar de volta todo o trabalho, e a gente conseguiu fazer. (ALUNA IV, 2019).
Transcorridas duas semanas, os alunos apresentaram a prévia do documentário. Na ocasião, cada aluno pôde opinar sobre quais as adequações necessárias para a finalização do documentário. Notou-se o uso repetido de imagens e a necessidade de regravar algumas cenas. Além disso, os alunos haviam optado por não haver fala nas dramatizações, porém, na exibição do documentário, ficou claro que as falas dariam um sentido maior nas cenas, assim como afirma a Aluna V: "Professora, é que a ideia principal era sem o áudio e só com a narração. Só que agora vendo, a gente acha que ficou melhor com o áudio".

Em meio a essa discussão, uma das alunas identificou que a turma estava tomando decisões, sem consultar a equipe de edição, o que fugia aos princípios do trabalho colaborativo.

Ah, tipo, era melhor com o áudio, mas tem que ver com [editor] também como é que fica para ele. Não é só a gente que vai fazer todas essas coisas. Vocês estão discutindo aí entre vocês, mas estão esquecendo de ver com ele. (ALUNA VI, 2019).

Por decisão unânime e com o aval da equipe de edição, agendaram-se novas gravações que se realizaram na semana seguinte. Aqui, vê-se uma retomada dos estudantes ao trabalho coletivo com uma abordagem colaborativa, onde não há divisão de tarefas e todos os membros se envolvem para o alcance do objetivo (TORRES; ALCANTARA; IRALA, 2004).

A prática social final consistiu na apresentação da versão final do documentário em sala de aula (GRANDI, 2019). Na ocasião, realizaram-se algumas perguntas sobre as experiências e as impressões dos estudantes frente à atividade proposta. $\mathrm{Na}$ opinião dos estudantes, apesar de desafiadora, foi uma experiência inovadora:

Uma coisa nova. Mas a gente já usava vídeos em trabalhos, mas como foi proposto pela professora esse vídeo, a gente achou um pouco complicado até por causa do tema que a gente estava trabalhando. Eu achei que foi muito bom essa experiência. (ALUNO II, 2019).

Sendo assim, ainda que desafiadora, a prática pedagógica abordada trouxe aos educandos novas experiências, que os conduziram a novos olhares sobre o processo de construção de conhecimento em que estão inseridos. Mesmo em se tratando da versão final do trabalho, os alunos encontraram diversos pontos que poderiam ser melhorados ou reorganizados em uma próxima oportunidade, o que configura uma postura de criticidade do aluno. Pode-se dizer que o desenvolvimento da criticidade do educando é 
também uma contribuição do uso de metodologias ativas em sala de aula.

\section{Conclusão}

Ao longo do desenvolvimento da pesquisa, notou-se que os conhecimentos prévios dos educandos, na área de produção de vídeo eram vastos, visto que os alunos já haviam feito outras produções de vídeos, bem como estavam familiarizados com o tema.

A temática proposta por eles, embora fosse do interesse de todos, exigiu uma extensa pesquisa sobre o tema. O uso de metodologias ativas, como a produção de vídeo em História, trouxe a necessidade de divisão e compartilhamento de ideias e informações no grande grupo, o que promoveu o trabalho coletivo em sala de aula, facilitando o desenvolvimento desta pesquisa e, por consequência, a absorção de conteúdo.

No decorrer do trabalho, os alunos foram adquirindo a maturidade e a autonomia necessárias para o desenvolvimento do trabalho coletivo. Por essa razão, pode-se dizer que, em certos momentos, o trabalho foi cooperativo, ou seja, com divisão de tarefas, e, em outros, foi colaborativo, onde todos realizaram todas as atividades.

Os momentos de cooperação serviram como um primeiro passo no desenvolvimento do trabalho coletivo e possibilitaram aos estudantes a autonomia e maturidade necessárias para migrar do cooperativismo ao colaborativismo. Ao passar para o trabalho colaborativo, os alunos obtiveram sucesso na produção de vídeo.

A mediação docente nesse processo, tornou-se imprescindível, uma vez que cabia ao mediador conduzir os alunos no processo dialógico de construção de ideias e conhecimento, além de proporcionar momentos de reflexão sobre a própria prática aos alunos como, por exemplo, com rodas de conversa e exibição de prévia do documentário.

Um dos desafios a essa prática pedagógica refere-se à falta de entrosamento e participação de professores de outras disciplinas. Os trabalhos poderiam convergir para um mesmo fim, nesse caso, a produção do documentário, evitando o sentimento de acúmulo de tarefas que os alunos relataram sentir.

Como proposta de trabalho futuro, sugere-se que se desenvolva uma pesquisa voltada aos professores, com foco no trabalho coletivo e no uso de metodologias ativas em sala de aula. Práticas colaborativas/ cooperativas, quando adotadas em conjunto pelo corpo docente, podem ampliar o alcance dos objetivos e da formação integral do educando, tornando o processo de aprendizagem mais significativo, uma vez que propicia a interlocução entre os componentes curriculares.

Quanto à pergunta inicial desta pesquisa: de que forma o uso de metodologias ativas, como a produção de vídeo, promove o trabalho coletivo em sala de aula, pode-se afirmar que o uso de metodologias ativas ainda se apresenta como um grande desafio à educação, pois convida os alunos e principalmente os professores, a saírem de sua zona de conforto e aventurarem-se em novas áreas ainda inóspitas a alguns deles.

Porém, ao passo que é desafiadora, essa abordagem pedagógica propicia o desenvolvimento crítico e reflexivo aos educandos, tirando-os do estado de inércia e conduzindo-os ao movimento, tornando-os protagonistas de seu próprio processo de construção de conhecimento.

Durante o trabalho, foi possível perceber que as metodologias ativas, como a produção de vídeo, promovem o trabalho coletivo em duas esferas. $\mathrm{Na}$ primeira, em relação aos seres humanos com mídias, foi possível perceber que a interação entre os atores humanos (estudantes) e não humanos (recursos, fontes e materiais), instigou os participantes a avançarem por campos muitas vezes inóspitos. Mas, ao sair da zona de conforto, novos conhecimentos foram adquiridos como, por exemplo, o uso e manuseio dos equipamentos e técnicas de edição de vídeos.

Além disso, nas exposições e discussões sobre o produto final (o vídeo), novamente essas relações se mostraram eficientes, fazendo com que os atores humanos mudassem ou firmassem suas percepções acerca do meio que os cerca e de sua realidade social.

$\mathrm{Na}$ segunda esfera, as metodologias ativas proporcionaram o trabalho coletivo entre atores humanos, por meio de interações sociais como: discussões sobre o roteiro e demais etapas a seguir, companheirismo e coletividade na organização de cenário e filmagem das cenas e mesmo nas interlocuções em cada etapa. Além disso, o compartilhamento de informações e resultados das pesquisas individuais ao grande grupo proporcionou a construção coletiva de conhecimentos sobre o fato e proporcionou que estudantes e mediador estivessem em um mesmo papel de protagonismo no processo.

\section{Referências}

ANDRADE, F. V. Ensino de história frente às tecnologias digitais: um olhar sobre a prática. Revista História Hoje, v. 7, p. 172-195, 2018. DOI: 10.20949/ 
rhhj.v7i14.363. Disponível em: https://rhhj.anpuh. org/RHHJ/article/view/363. Acesso em: 29 nov. 2020.

BAGNO, M. Pesquisa na escola: o que é, como se faz. 22. ed. São Paulo: Loyola, 2008.

BARROS, C. H. F. Ensino de história, memória e história local. Criar Educação, v. 2, n. 2, p. 1-23, 2013. Disponível em: http://periodicos.unesc.net/criaredu/ article/view/1247. Acesso em: 5 set. 2019.

BORBA, M. C.; OECHSLER, V. Tecnologias na educação: o uso dos vídeos em sala de aula. Revista Brasileira de Ensino de Ciência e Tecnologia, v. 11, p. $181-213,2018$. DOI: $10.3895 /$ rbect.v11n2.8434. Disponível em: https://periodicos.utfpr.edu.br/rbect/ article/view/8434. Acesso em: 10 out. 2019.

BORBA, M. C.; PENTEADO, M. G. Informática e educação matemática. 3. ed. Belo Horizonte: Autêntica, 2007.

BORBA, M. C.; VILLARREAL, M. E. Humans-WithMedia and the reorganization of mathematical thinking: information and communication technologies, modeling, experimentation and visualization. New York: Springer, 2005. v. 39.

BLOCH, M. Apologia da história ou o oficio do historiador. Rio de Janeiro: Jorge Zahar, 2002.

CHIARI, A. S. S. O papel das tecnologias digitais em disciplinas de álgebra linear a distância: possibilidades, limites e desafios. 2015. $200 \mathrm{f}$. Tese (Doutorado em Educação Matemática) - Universidade Estadual Paulista Júlio de Mesquita Filho, Rio Claro, 2015.

COTRIM, G.; RODRIGUES, J. Saber e fazer história. São Paulo: Saraiva, 2014.

DIESEL, A.; BALDEZ, A. L. S.; MARTINS, S. N. Os princípios das metodologias ativas de ensino: uma abordagem teórica. Revista Thema, v. 14, p. $268-288,2017$. DOI: $10.15536 /$ thema.14.2017.268-288.404. Disponível em: https:// periodicos.ifsul.edu.br/index.php/thema/article/ view/404/295. Acesso em: 15 out. 2019.

FREIRE, P. Pedagogia da autonomia: saberes necessários à prática educativa. 15. ed. São Paulo: Paz e Terra, 2000.

FUNARI, P. P. A. Ensaio sobre a retórica, a argumentação e a historiografia. Revista Eletrônica Antiguidade Clássica, v. 7, n. 1, p. 140-149, 2011. Disponível em: https://antiguidadeclassica.com.br/ website/edicoes/setima_edicao/10.pdf. Acesso em: 8 out. 2020.

GASPARIN, J. L. Uma didática para a pedagogia histórico-crítica. 3. ed. Campinas: Autores Associados, 2005.

GERMINARI, G. D.; BUCZENKO, G. História local e identidade: um estudo de caso na perspectiva da educação histórica. História \& Ensino, v. 18, p. 125-142, 2012. DOI: 10.5433/2238-3018.2012v18n2p125. Disponível em: https://www.uel.br/revistas/uel/index.php/histensino/ article/view/12593. Acesso em: 8 out. 2020.

GRANDI, M. Pesquisa-Ação: Documentário em História "O Mistério da morte de Ivo Renaux". 2019. 1 vídeo (6 min $56 \mathrm{~s}$ ). Disponível em: https://www. youtube.com/watch? $\mathrm{v}=\mathrm{zviUvW} 1 \mathrm{ipnI}$. Acesso em: 10 nov. 2021.

GRANDI, M.; OECHSLER, V. Metodologias ativas e a sala de aula: a produção de vídeo como pesquisa e prática pedagógica em História. In: SEMANA DE PESQUISA E PRÁTICA PEDAGÓGICA, 2019, Gaspar. Anais [...]. Gaspar: IFSC, 2019.

GUARINELLO, N. L. História científica, história contemporânea e história cotidiana. Revista Brasileira de História, v. 24, n. 48, p. 13-38, 2004. DOI: $10.1590 /$ S0102-01882004000200002. Disponível em: https://www.scielo.br/j/rbh/a/ HgbbbFDvxfpHrYbF5MppKDv/?lang=pt. Acesso em: 8 out. 2020 .

HAMPE, B. Escrevendo um documentário. New York: Henry Holt, 1997.

KLEIN, J. J. Estudo sobre ferramentas de informação e comunicação aliado a estratégias pedagógicas. Revista Liberato, v. 13, n. 19, p. 7-18, 2012. Disponível em: https://revista.liberato.com.br/ojs_lib/index.php/ revista/article/view/81/73. Acesso em: 5 nov. 2019.

LEITE, C. A. R.; LEITE, E. C. R.; PRANDI, L. R. A aprendizagem na concepção histórico cultural. Akrópolis, v. 17, n. 4, p. 203- 210, out./dez. 2009. Disponível em: https://revistas. unipar.br/index.php/akropolis/article/ view/2900\#: :text=Concluiu\%2Dse\%20que\%20 o\%20desenvolvimento,ocupam\%20lugar\%20de\%20 import\%C3\%A2ncia\%20no. Acesso em: 15 out. 2019.

LÉVY, P. As tecnologias da inteligência: o futuro do pensamento na era da informática. Rio de Janeiro: Editora 34, 1993. 
LOVATO, F. L. et al. Metodologias ativas de aprendizagem: uma breve revisão. Acta Scientiae, v. 20 , n. 2, p. 154-171, 2018. DOI: 10.17648/acta. scientiae.v20iss2id3690. Disponível em: https:// www.researchgate.net/publication/327924688 Metodologias_Ativas_de_Aprendizagem_Uma_ Breve_Revisao. Acesso em: 10 out. 2019.

LÚCIDE, D.; KALIL, T. Oficina: Como realizar entrevista/História Oral. In: SEMANA ENVOLVER, 2012, Jequitinhonha. Anais [...]. Jequitinhonha: UFVJM, 2012.

MORAN, J. Metodologias ativas e modelos híbridos na educação. In: YAEGASHI, S. F. R. Novas tecnologias digitais: reflexões sobre mediação, aprendizagem e desenvolvimento. Curitiba: CRV, 2017. p. 23-36.

OECHSLER, V. Vídeos e educação matemática: um olhar para dissertações e teses. In: ENCONTRO BRASILEIRO DE ESTUDANTES DE PÓSGRADUAÇÃO EM EDUCAÇÃO MATEMÁTICA, 19., 2015, Juiz de Fora. Anais [...]. Juiz de Fora: UFJF, 2015.

OECHSLER, V.; FONTES, B. C.; BORBA, M. C. Etapas da produção de vídeos por alunos da educação básica: uma experiência na aula de matemática. Revista Brasileira de Educação Básica, v. 1, p. 7180, 2017. Disponível em: https://rbeducacaobasica. com.br/etapas-da-producao-de-videos-por-alunosda-educacao-basica-uma-experiencia-na-aula-dematematica/. Acesso em: 20 ago. 2019.

OECHSLER, V. Comunicação multimodal: produção de vídeos em aulas de Matemática. 2018. 312 f. Tese (Doutorado em Educação Matemática)
- Universidade Estadual Paulista Júlio de Mesquita Filho, Rio Claro, 2018.

PEIXOTO, J.; CARVALHO, R. M. A. Os desafios de um trabalho colaborativo. Educativa, v. 10, p. 191210, 2007. DOI: 10.18224/educ.v10i2.459. Disponível em: http://seer.pucgoias.edu.br/index.php/educativa/ article/view/459. Acesso em: 6 set. 2019.

SAVIANI, D. Pedagogia histórico-crítica: primeiras aproximações. 9. ed. Campinas: Autores Associados, 2005.

SOUTO, D. P. L. Transformações expansivas em um curso de Educação Matemática a distância online. 2013. 279 f. Tese (Doutorado em Educação Matemática) - Universidade Estadual Paulista Júlio de Mesquita Filho, Rio Claro, 2013.

TIKHOMIROV, O. K. The psychological consequences of computerization. In: WERTSCH, J. V. The concept of activity in soviet psychology. New York: M. E. Sharpe, 1981. p. 256-278.

TORRES, P. L.; ALCANTARA, P. R. C.; IRALA, E. A. F. Grupos de consenso: uma proposta de aprendizagem colaborativa para o processo de ensino - aprendizagem. Revista Diálogo Educacional, v. 5, n. 13, p. 134-150, 2004. Disponível em: https://periodicos.pucpr.br/index. $\mathrm{php} /$ dialogoeducacional/article/view/7052/6932. Acesso em: 10 set. 2019.

TORRES, P. L.; IRALA, E. A. F. Aprendizagem colaborativa: teoria e prática. In: TORRES, P. L. (org.). Complexidade: redes e conexões na produção do conhecimento. Curitiba: Senar, 2014, p. 61-93. 